\title{
Early and long-term outcome of infants born extremely preterm
}

\author{
Samantha Johnson, ${ }^{1}$ Neil Marlow ${ }^{2}$
}

${ }^{1}$ Department of Health Sciences, University of Leicester, Leicester, UK ${ }^{2}$ Institute for Women's Health, University College London, London, UK

\section{Correspondence to Dr Samantha Johnson Department of Health Sciences, University of Leicester, Centre for Medicine, University Road, Leicester LE1 7RH, UK; sjj19@le.ac.uk}

Received 12 May 2016 Accepted 12 July 2016 Published Online First 10 August 2016

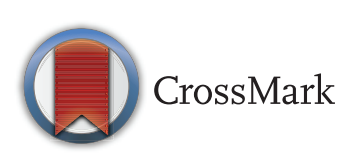

To cite: Johnson S, Marlow N. Arch Dis Child 2017;102:97-102.

\section{ABSTRACT}

There is no question that birth at extremely low gestational ages presents a significant threat to an infant's survival, health and development. Growing evidence suggests that gestational age may be conceptualised as a continuum in which births before 28 weeks of gestation (extremely preterm: EP) represent the severe end of a spectrum of health and developmental adversity. Although comprising just $1 \%-2 \%$ of all births, EP deliveries pose the greatest challenge to neonatal medicine and to health, education and social services for the provision of ongoing support for survivors with additional needs. Studying the outcomes of these infants remains critical for evaluating and enhancing clinical care, planning long-term support and for advancing our understanding of the life-course consequences of immaturity at birth. Here we review literature relating to early and long-term neurodevelopmental, cognitive, behavioural and educational outcomes following EP birth focusing on key themes and considering implications for intervention.

\section{SURVIVAL AND NEONATAL OUTCOMES}

Neonatal survival is in continuous evolution, particularly at extremely low gestational ages. Survival at the lowest gestational ages (23-24 weeks) varies in population-based reports, primarily as different countries and hospitals assume contrasting stances as to the provision of active care (figure 1). Data from the USA most vividly demonstrate this variation; ${ }^{1}$ survival is highest in situations where more active obstetric and neonatal management is practised. $^{2}$ Interpreting survival without knowing the proportion of live births for whom active stabilisation was given is impossible and reports need to be explicit with regard to this. Using population data, neonatal survival in England after birth at 2225 weeks gestation increased by 13\% from 39\% (95\% CI $35 \%$ to $43 \%$ ) in 1995 to $52 \%$ (95\% CI $49 \%$ to $55 \%)$ in $2006,{ }^{3}$ and routine data suggest that has continued since. Survival is highly dependent on the place of birth, being better in larger neonatal services which more frequently undertake active care. ${ }^{4}$ In contrast, the prevalence of major neonatal morbidities-bronchopulmonary dysplasia, periventricular brain injury, retinopathy of prematurity and sepsis/necrotising enterocolitis-is essentially unchanged, despite continually evolving and less invasive strategies. ${ }^{3}$

\section{NEURODEVELOPMENTAL OUTCOMES OVER THE FIRST 2 YEARS}

Most neonatal services now monitor neurodevelopmental outcomes to 2-3 years. Using similar techniques, EPICure-2 demonstrated increases in survival without disability for babies admitted for neonatal care at 23 weeks (OR 1.4 (95\% CI 0.68 to 2.7)), 24 weeks (OR 1.8 (95\% CI 1.2 to 2.7$)$ ) and 25 weeks gestation (OR 1.9 (95\% CI 1.4 to 2.6)) between 1995 and 2006, whereas the prevalence of severe disability was unchanged $(18 \% \quad(95 \%$ CI $14 \%$ to $24 \%$ ) in 1995 and $19 \%$ (95\% CI $14 \%$ to $23 \%$ ) in 2006). ${ }^{5}$ Key conditions are cerebral palsy (CP), developmental impairment and, to a lesser extent, sensory impairment. The prevalence of such impairments among survivors appears to be independent of differences in survival between studies. ${ }^{6}$ Although the individual predictive value of early assessments is relatively poor, in population terms the proportions with severe and moderate impairment have remained very stable over childhood, ${ }^{7}$ making such data useful to support parental counselling.

The prevalence of $\mathrm{CP}$ in the extremely preterm (EP) population and in those of extremely low birth weight (ELBW; $<1000 \mathrm{~g}$ ) is declining across Europe. ${ }^{8}$ In the EPICure-2 study of birth $\leq 26$ weeks gestation in 2006, the proportion with moderate to severe CP (with Gross Motor Function Classification System levels 3-5) comprised 9\% of survivors at $22-23$ weeks, $5 \%$ at 24 weeks, falling to $2 \%$ at 26 weeks. Most survivors with neurological abnormality had only mild functional impairment.

Changes in the prevalence of developmental impairment over time are more challenging to assess as consecutive editions of developmental tests are not equivalent. The current edition of the Bayley Scales (the Bayley-III) in particular produces higher scores compared with its predecessor and seems to be less discriminatory in the lower performance range, ${ }^{9}$ clearly the important area of assessment. However, using a correction algorithm, the EPICure-2 study demonstrated an 8 (95\% CI 5 to 10) point increase in scores between 1995 and 2006 at 2-3 years of age, particularly for those born at 24 and 25 weeks of gestation. It is unclear as yet whether this will translate into improved school-age outcomes.

Sensory impairments are much less prevalent and are less well understood. In EPICure-2, only 1\% of survivors had severe visual or hearing impairments, and moderate impairment was found in $6 \%$ and $5 \%$, respectively, at $2-3$ years. The origin of these impairments is unclear. Most visual impairment, for example, appears to be central in origin rather than the result of retinopathy, which is in the main treatable. Important somatic impairments-longterm respiratory impairment ${ }^{10}$ or increases in cardiovascular risk ${ }^{11}$ for example-are common in such populations, but it is difficult to quantify their 
Figure 1 Survival of live births in large population-based studies 2003-2011. NICHD, National Institute of Child Health and Human Development; w, weeks.
Live births 2003-2011 Per cent

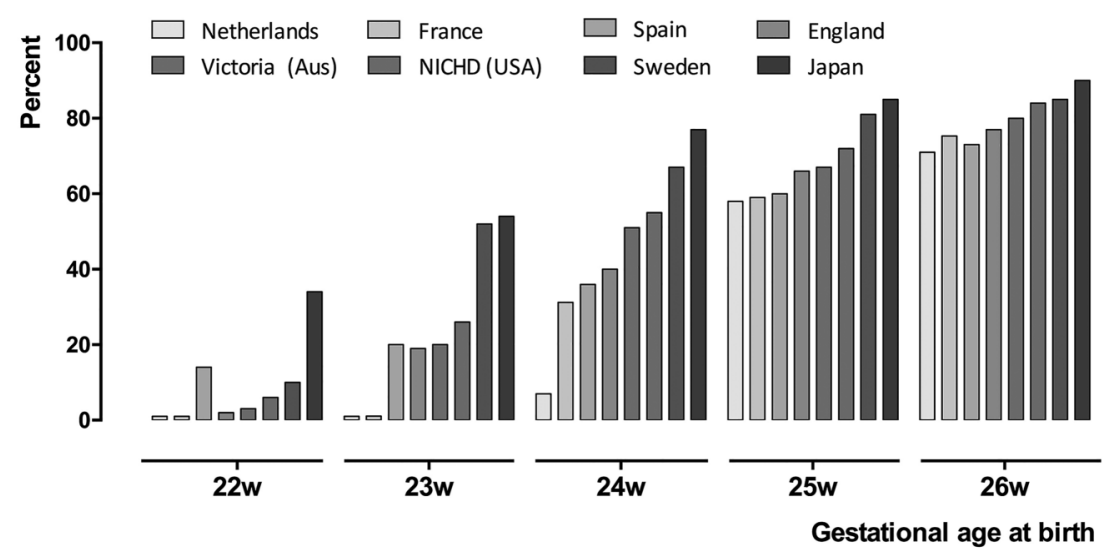

impact in infancy and early childhood, although these may become more important in later life.

\section{OUTCOMES IN CHILDHOOD AND ADOLESCENCE Cognition}

Cognitive impairments far surpass rates of neurosensory disabilities in EP populations. Meta-analyses have identified weighted mean differences of 11-12 IQ points in preterm versus termborn children, equating to $0.7 \mathrm{SD}$ to $0.8 \mathrm{SD}$ deficits relative to controls. $^{12}{ }^{13}$ IQ is significantly associated with gestational age at birth, with a 14-point weighted mean difference $(\sim 1$ SD) reported for cohorts with mean gestational age $<28$ weeks. ${ }^{13}$ Even greater deficits have been reported for those born nearer the limits of viability with a 20 -point $(95 \%$ CI -23 to -17$)$ deficit for children born $<26$ weeks, of which $40 \%$ had intellectual disability compared with just $1.3 \%$ of controls at 11 years of age. ${ }^{14}$ It is as yet unclear whether there is a linear relationship between IQ and gestational age for those born below 33 weeks only ${ }^{15}$ or for all gestations below full term, ${ }^{13}$ or whether there is an exponential relationship with gestational age as evidenced in educational data. ${ }^{16}$ Low IQ is the product of social disadvantage, genetic influences and prematurity with the effects of environmental factors exerting a greater role over time.

There has been increasing interest in studying neuropsychological outcomes and, in particular, in understanding the specific cognitive deficits associated with EP birth in order to elucidate targets for intervention. Numerous studies have reported significant deficits in a range of basic cognitive processes, including short-term memory, processing speed, visual-perceptual skills, sensorimotor integration and attention in EP children relative to term-born controls. ${ }^{17}$ Such deficits have been observed from school entry through adolescence. ${ }^{17-20}$ In particular, there is growing interest in executive functions, a set of inter-related cognitive processes that allow individuals to respond flexibly to the environment and to engage in purposeful, goal-directed behaviour. Such processes are variously defined and often include, but are not limited to, inhibition, planning, shifting or cognitive flexibility, working memory and verbal fluency. Identifying pure measures of executive functions and the taskdependent nature of performance on such tests can make comparisons between studies problematic. However, meta-analyses of data from studies of very preterm (VP; $<32$ weeks)/very low birthweight (VLBW; $<1500 \mathrm{~g}$ ) cohorts have reported small to medium effect sizes $(0.25$ SD to $0.57 \mathrm{SD})$ for deficits in inhibition, working memory, planning, cognitive flexibility and verbal fluency, ${ }^{21}{ }^{22}$ with greater deficits observed in children born
$<26$ weeks gestation. ${ }^{21}$ Deficits in executive functions have also been observed on parent and teacher reports in EP/ELBW children and appear to persist over time. ${ }^{19} 2324$ It is also thought that these may be core cognitive deficits that underlie much of the psychiatric morbidity and learning difficulties in this population and are thus being explored as targets for intervention.

\section{Behavioural, social and emotional outcomes}

Compared with neurodevelopmental sequelae, there is much less evidence regarding early behavioural, social and emotional outcomes. Where studies exist, these have typically focused on outcomes from 2 years of age when the availability of standardised rating scales affords a more reliable assessment. Studies using these measures have shown that EP children are at risk for a range of behavioural sequelae with greatest evidence for attention problems and poor socioemotional competence in the preschool years. ${ }^{25}$ Three studies using the Strengths and Difficulties Questionnaire have reported that EP children have a significant excess of problems in all four domains assessed (emotional, conduct, inattention/hyperactivity and peer relationship problems) and, in each study, attention and peer relationship problems were most frequently reported. ${ }^{26-28}$ Similarly, using a different measure, ELBW children had significantly more attention deficit/hyperactivity disorder (ADHD) symptoms, peer relationship problems and poorer social competence as rated by their kindergarten teachers at 5 years of age, and a 2.5 times increased risk for ADHD reported by parents, with no excess of problems in other domains. $^{29}$

Authors have also reported that $21 \%-41 \%$ of EP children screen positive for the risk for autism spectrum disorders (ASD) at 2 years corrected age on the Modified Checklist for Autism in Toddlers (M-CHAT) ${ }^{30}$ parent questionnaire. ${ }^{31} 32$ However, although these rates are higher than the $9 \%$ generally reported in unselected samples, ${ }^{30} 33$ the true proportion with ASD is likely to be lower as infants may screen positive due to the range of neurodevelopmental impairments commonly observed after EP birth rather than autistic features per se. ${ }^{31} 32{ }^{34}$ Where the M-CHAT follow-up interview is used to improve specificity, as prescribed by the authors, a positive screen rate of $13 \%$ has been reported in EP infants and a $1.8 \%$ prevalence of diagnoses at 2-4 years. ${ }^{35}$ The M-CHAT is therefore likely to identify children at risk for a range of developmental disorders and should be used with caution when screening for ASD until its predictive validity for later diagnoses is ascertained.

These early outcomes have continuity with the larger number of studies in middle childhood and adolescence from which a 
clear preterm behavioural phenotype characterised by attention, anxiety and social difficulties has emerged. ${ }^{36}$ Although prevalence estimates for clinically significant problems vary widely using parent-completed or teacher-completed rating scales, ${ }^{25}$ prevalence estimates for psychiatric disorders are more consistent at $23 \%-24 \%{ }^{37} 38$ equating to a 3 times increased risk compared with term-born controls. ${ }^{25} 39$ This behavioural phenotype is also evidenced in the pattern of psychiatric disorders observed in EP cohorts, in which there is a significant excess of ADHD (typically symptoms of inattention rather than hyperactivity/ impulsivity), emotional disorders (typically anxiety rather than depression) and ASD (typically problems with social interaction and communication). ${ }^{36}$ Notably, the excess of these disorders occurs in the absence of an increased risk for conduct disorders, a pattern that is also observed using behavioural rating scales. ${ }^{40}$ The international and temporal consistency in outcomes suggests that universal biological factors underlie the development of behavioural, social and emotional problems in this population, and the association of psychiatric disorders with cognitive impairments and indices of brain structure and function suggests that these may be mediated by adverse neurodevelopment following EP birth. ${ }^{36} 38{ }^{41}$ Studies have also shown that the commonly observed deficits in executive functions described above may mediate the relationship between EP birth and psychiatric morbidity, in particular, attention problems. ${ }^{29} 42-44$

\section{Educational outcomes}

Large population-based studies of the effects of gestation at birth have shown that EP children are less likely to complete basic school education and are more likely to have poorer academic attainment than both their term-born peers and their more mature preterm counterparts. ${ }^{45}{ }^{46}$ Birth cohort studies have also shown that these deficits are evident on both standardised attainment tests ${ }^{14}$ 47-50 and teacher reports ${ }^{23}$ 49-51 and from the earliest years of schooling throughout adolescence. There are also significantly and substantially increased rates of learning difficulties, ${ }^{14} 474852$ even among those without neurosensory impairments and after adjustment for socioeconomic factors. Consequently, 39\%-62\% of EP/ELBW children are reported to have special educational needs (SEN); ${ }^{14} 4752$ thus, it is unsurprising that after neonatal care the greatest costs associated with support for EP children lie in education. ${ }^{53}$

Data from the UK EPICure Study of births $<26$ weeks gestation illustrate the deficits observed in educational outcomes. At 6 years of age, $50 \%$ of EP children were rated by teachers as having below average attainment compared with $5 \%$ of termborn classmates (OR 17.9, 95\% CI 8.3 to 38.9 ), ${ }^{54}$ with a similar deficit observed at 11 years of age $(50 \%$ vs $5 \%$; OR
18.2, $95 \%$ CI 8.0 to 41.4$).{ }^{51}$ Attainment in all school subjects was also significantly poorer than term-born controls (figure 2). Overall, $30 \%$ of EP children had learning difficulties in reading versus $2 \%$ of their term-born classmates (OR 22; 95\% CI 6.6 to $7.0)$ and $44 \%$ versus $1.3 \%$ had mathematics learning difficulties (OR 59; 95\% CI 14 to 243). ${ }^{14}$ These data and those of other studies show that of all subjects studied at school, EP children appear to have greatest difficulties in mathematics (figure 2) ${ }^{47} 52$ and, unlike reading difficulties, these are not fully accounted for by low IQ. Similar to the findings relating to behavioural outcomes, specific deficits in executive functions may also underlie VP children's difficulties with mathematics. ${ }^{43} 5255$

\section{OUTCOMES IN ADULTHOOD}

The majority of data relating to outcomes in adulthood are provided by registry-based studies or are from VP/VLBW cohorts assembled in the 1970s and 1980s. Although these have fewer EP survivors than contemporary cohorts, they do provide an index of what we might expect life to be like for EP adults today. These typically show a clear gestational age-related gradient in outcomes with EP adults remaining at increased risk for $\mathrm{CP}$ and other neurosensory disabilities. ${ }^{56-59}$ Recent reports also show that VP/VLBW adults do not outgrow their cognitive problems and that deficits are still present to a similar magnitude as in earlier assessments, including significantly poorer performance on tests of IQ and executive functions and increased rates of intellectual disabilities. ${ }^{60} 61$ The profile of cognitive abilities in early adulthood is also similar to that reported in childhood. $^{61}$

The educational attainment of VP/VLBW young adults is also generally poorer than term-born adults with fewer completing higher education and a greater proportion opting to undertake vocational education or training. ${ }^{59} 61$ There is also evidence of an increased risk for psychiatric disorders in adulthood, including ASD, ${ }^{59}$ ADHD $^{62} 63$ and mood disorders ${ }^{59} 6465$ demonstrating continuity with outcomes reported in childhood (figure 3 ). A number of studies have also reported reduced social interactions and risk-taking behaviours in VP/VLBW adolescents ${ }^{66} 67$ and higher introversion, autistic features and neuroticism which may underpin some of the social difficulties in this population. Fewer VP/VLBW adults are also married or cohabiting and reproductive rates may be lower than observed in term-born adults. ${ }^{57}$ Longitudinal studies have also shown that cognitive and behavioural problems in VP/VLBW individuals are more stable over time than in adults born at term. ${ }^{60} 68$

Despite the persistence of health and neurodevelopmental sequelae, VP/VLBW adults are perhaps functioning better than might have once been expected with a significant majority
Figure 2 Mean difference $(95 \% \mathrm{Cl})$ in teacher ratings of academic attainment for 145 extremely preterm children ( $<26$ weeks gestation) and 171 term-born controls assessed at 11 years of age in the UK \& Ireland EPICure Study. ${ }^{11}$

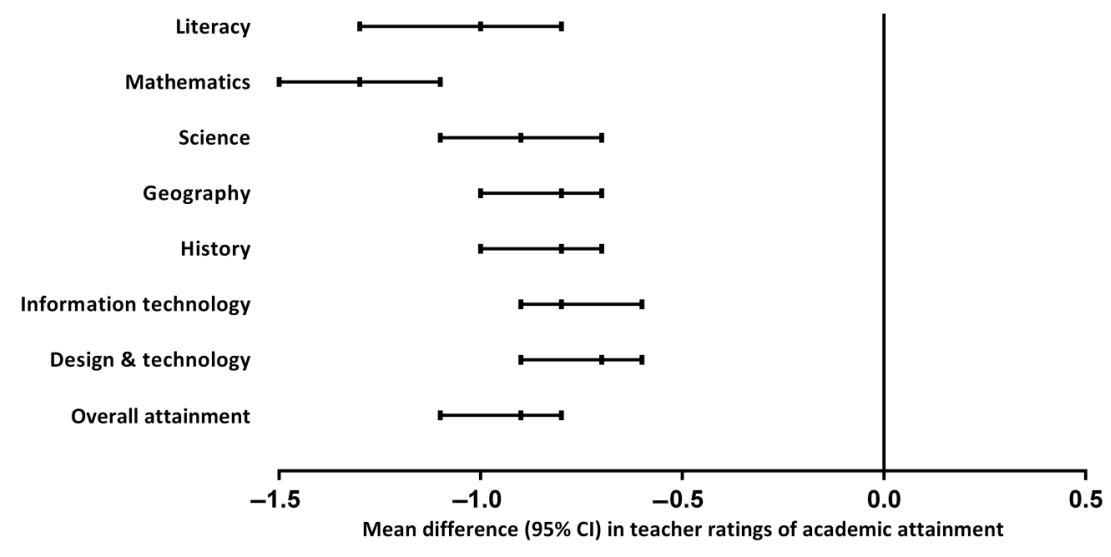


Figure 3 Psychiatric morbidity in adolescents and young adults born from Lindstrom et al $\left.{ }^{64}\right)$. very preterm (figure created using data

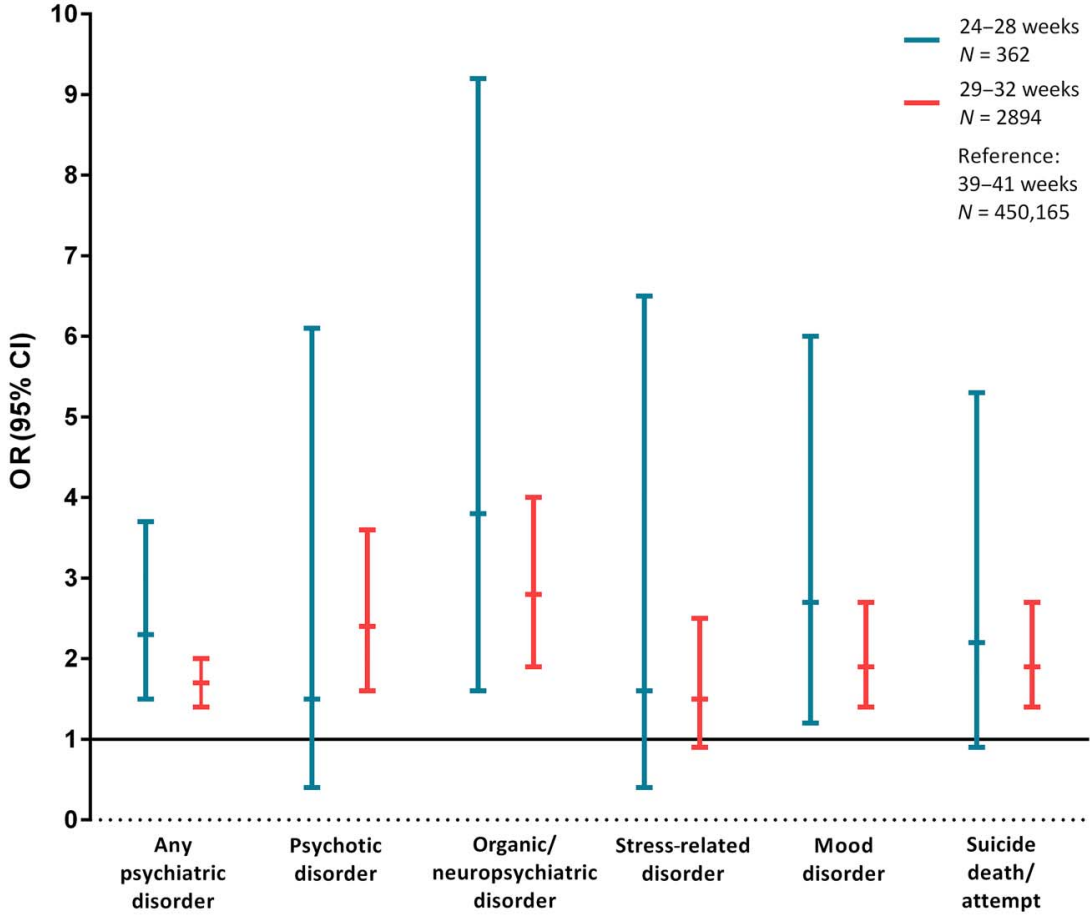

leading independent and self-supportive lives. ${ }^{57}$ Although VP/ VLBW adults may have lower wealth and job-related income, they have similar rates of employment to term-born adults ${ }^{56} 59$ and self-perceived quality of life is similar to controls with many managing the transition to adulthood as well as adults born at more mature gestations. ${ }^{57}$ These results are encouraging and the clinical and academic communities are eagerly anticipating publication of outcomes in adulthood for the earliest EP cohorts assembled in the 1990s and beyond.

\section{IMPLICATIONS FOR INTERVENTION}

The persistence of neurodevelopmental sequelae from infancy to adulthood underscores the need for preventive intervention. Increased recognition of the association of sensitive and responsive parenting with later school-age outcomes suggests that interventions to improve parent-infant interaction might be beneficial. ${ }^{69}$ However, evidence for the efficacy of post-discharge programmes for enhancing cognitive and developmental outcomes is limited; even where short-term effects have been reported, these are rarely sustained beyond the period of intervention delivery and into school age. ${ }^{70}$ In recent years, attention has turned to the potential for working memory training to improve cognitive and educational outcomes in preterm populations. However, although these might show short-term gain in terms of improved working memory, there is as yet no evidence of generalisation to other outcomes either in preterm children or those with working memory deficits. ${ }^{71} 72$ Given the heterogeneity in outcomes and the wide range of deficits experienced by EP children, interventions that are delivered during the school years and those that target the multiple cognitive processes affected by EP birth may be beneficial. Such efforts might focus on the development of new population-specific interventions or on trialling the efficacy of existing teaching strategies in EP children.

Given the preterm behavioural phenotype described above, EP children are often characterised as anxious and inattentive, but not as hyperactive or disruptive in the classroom. As such,
EP children with difficulties may not come to the teacher's attention as readily as other children with externalising behaviour problems or with other SEN. Thus, informing education professionals about the special constellation of problems following EP birth may help them to identify those with difficulties and provide appropriate support in the classroom. ${ }^{73}$ From a parent's perspective, delaying school entry might be considered as a potential intervention to help improve their child's performance at school, especially for those who feel their child is developmentally immature and/or is born in the summer months. However, recent evidence suggests that delaying school entry is unlikely to benefit preterm children's academic attainment and that starting school at the age-appropriate time and ensuring support for those with difficulties may be more appropriate. ${ }^{74}$ However, more research is needed to provide a definitive answer as to whether delaying school entry might benefit children's academic, emotional and social outcomes in the long term.

\section{CONCLUSIONS}

Improved survival rates for EP births over recent decades have not yet been matched by clear evidence of a reduction in rates of neurodevelopmental disability. A high prevalence of intellectual disabilities, behavioural, social and emotional problems and learning difficulties continues to dominate the literature relating to childhood outcomes and recent reports have confirmed that these difficulties persist into adult life. Neuropsychological deficits appear to mediate the relationship between EP birth and long-term outcomes and may represent potential targets for intervention, though evidence for the long-term efficacy of early intervention efforts remains limited. Longitudinal studies with follow-up into adulthood are needed to determine the impact of EP birth in relation to contemporary care and to identify whether ongoing improvements in neonatal medicine have translated into improved outcomes across the lifespan. Although a substantial proportion of EP survivors are likely to need intervention to facilitate their performance at school and to support 
their mental health and well-being throughout childhood and adolescence, outcomes may be better than once anticipated with most EP adults living independently and with a good selfreported quality of life.

Contributors SJ and NM contributed equally to the drafting and revision of this manuscript.

Funding NM receives part funding from the Department of Health's National Institute for Health Research Biomedical Research Centre's funding scheme at University College London Hospital/UCL University College London.

Competing interests None declared.

Provenance and peer review Commissioned; externally peer reviewed.

\section{REFERENCES}

1 Rysavy MA, Li L, Bell EF, et al. Between-hospital variation in treatment and outcomes in extremely preterm infants. N Engl I Med 2015;372:1801-11.

2 Serenius $F$, Sjörs $G$, Blennow $M$, et al. EXPRESS study shows significant regional differences in 1-year outcome of extremely preterm infants in Sweden. Acta Paediatr 2014:103:27-37

3 Costeloe KL, Hennessy EM, Haider $S$, et al. Short term outcomes after extreme preterm birth in England: comparison of two birth cohorts in 1995 and 2006 (the EPICure studies). BMJ 2012;345:e7976.

4 Marlow N, Bennett C, Draper ES, et al. Perinatal outcomes for extremely preterm babies in relation to place of birth in England: the EPICure 2 study. Archives Dis Child Fetal Neonatal Ed 2014;99:F181-8.

5 Moore T, Hennessy EM, Myles J, et al. Neurological and developmental outcome in extremely preterm children born in England in 1995 and 2006: the EPICure studies. BMJ 2012:345:e7961.

6 Marlow N. Interpreting regional differences in neonatal outcomes for extremely preterm babies. Acta Paediatr 2014;103:4-5.

7 Johnson S, Fawke J, Hennessy E, et al. Neurodevelopmental disability through 11 years of age in children born before 26 weeks of gestation. Pediatrics 2009;124: e249-57.

8 Sellier E, Platt MJ, Andersen GL, et al. Decreasing prevalence in cerebral palsy: a multi-site European population-based study, 1980 to 2003. Dev Med Child Neurol 2016;58:85-92.

9 Moore T, Johnson S, Haider S, et al. Relationship between test scores using the second and third editions of the Bayley Scales in extremely preterm children. J Pediatr 2012;160:553-8.

10 Fawke J, Lum S, Kirkby J, et al. Lung function and respiratory symptoms at 11 years in children born extremely preterm: the EPICure study. Am J Respir Crit Care Med 2010;182:237-45.

11 McEniery CM, Bolton CE, Fawke J, et al. Cardiovascular consequences of extreme prematurity: the EPICure study. I Hypertens 2011;29:1367-73.

12 Bhutta A, Cleves M, Casey P, et al. Cognitive and behavioral outcomes of school-aged children who were born preterm: a meta-analysis. JAMA 2002;288:728-37.

13 Kerr-Wilson CO, Mackay DF, Smith GC, et al. Meta-analysis of the association between preterm delivery and intelligence. J Public Health (Oxf) 2012;34:209-16.

14 Johnson S, Hennessy E, Smith R, et al. Academic attainment and special educational needs in extremely preterm children at 11 years. The EPICure Study. Archives Dis Child Fetal Neonatal Ed 2009:94:F283-F9.

15 Wolke D, Strauss VY, Johnson $S$, et al. Universal gestational age effects on cognitive and basic mathematic processing: 2 cohorts in 2 countries. J Pediatr 2015:166:1410-16.e1-2.

16 MacKay DF, Smith GC, Dobbie R, et al. Gestational age at delivery and special educational need: retrospective cohort study of 407,503 schoolchildren. PLoS Med 2010;7:e1000289.

17 Anderson PJ. Neuropsychological outcomes of children born very preterm. Semin Fetal Neonatal Med 2014;19:90-6.

18 Anderson PJ, De Luca CR, Hutchinson E, et al. Attention problems in a representative sample of extremely preterm/extremely low birth weight children. Dev Neuropsychol 2011;36:57-73.

19 Burnett AC, Scratch SE, Lee KJ, et al. Executive function in adolescents born $<1000$ g or <28 weeks: a prospective cohort study. Pediatrics 2015;135:e826-34.

20 Orchinik LJ, Taylor HG, Espy KA, et al. Cognitive outcomes for extremely preterm/ extremely low birth weight children in kindergarten. J Int Neuropsychol Soc 2011:17:1067-79.

21 Mulder H, Pitchford NJ, Hagger MS, et al. Development of executive function and attention in preterm children: a systematic review. Dev Neuropsychol 2009;34:393-421.

22 Aarnoudse-Moens CS, Weisglas-Kuperus N, van Goudoever JB, et al. Meta-analysis of neurobehavioral outcomes in very preterm and/or very low birth weight children. Pediatrics 2009;124:717-28.
23 Faroogi A, Hägglöf $B$, Serenius F. Behaviours related to executive functions and learning skills at 11 years of age after extremely preterm birth: a Swedish national prospective follow-up study. Acta Paediatr 2013;102:625-34.

24 Anderson PJ, Doyle LW. Executive functioning in school-aged children who were born very preterm or with extremely low birth weight in the 1990s. Pediatrics 2004;114:50-7.

25 Johnson S, Marlow N. Growing up after extremely preterm birth: lifespan mental health outcomes. Semin Fetal Neonatal Med 2014;19:97-104.

26 Delobel-Ayoub M, Kaminski M, Marret S, et al. Behavioural outcome at 3 years of age in very preterm infants: the EPIPAGE Study. Pediatrics 2006;117:1996-2005.

27 Elgen SK, Leversen KT, Grundt JH, et al. Mental health at 5 years among children born extremely preterm: a national population-based study. Eur Child Adolesc Psychiatry 2012;21:583-9.

28 Woodward LJ, Moor S, Hood KM, et al. Very preterm children show impairments across multiple neurodevelopmental domains by age 4 years. Archives Dis Child Fetal Neonatal Ed 2009;94:F339-44.

29 Scott MN, Taylor HG, Fristad MA, et al. Behavior disorders in extremely preterm/ extremely low birth weight children in kindergarten. J Dev Behav Pediatr 2012:33:202-13.

30 Robins DL, Fein D, Barton ML, et al. The Modified Checklist for Autism in Toddlers: an initial study investigating the early detection of autism and pervasive developmental disorders. J Autism Dev Disord 2001;31:131-44.

31 Moore $T$, Johnson $S$, Hennessy $E$, et al. Screening for autism in extremely preterm infants: problems in interpretation. Dev Med Child Neurol 2012;54:514-20.

32 Kuban KCK, O'Shea TM, Allred EN, et al. Positive screening on the Modified Checklist for Autism in Toddlers (M-CHAT) in extremely low gestational age newborns. J Pediatr 2009;154:535-40.

33 Guy A, Seaton SE, Boyle EM, et al. Infants born late/moderately preterm are at increased risk for a positive autism screen at 2 years of age. $J$ Pediatr 2015;166:269-75.e3.

34 Luyster RJ, Kuban KCK, O'Shea TM, et al. The Modified Checklist for Autism in Toddlers in extremely low gestational age newborns: individual items associated with motor, cognitive, vision and hearing limitations. Paediatr Perinat Epidemiol 2011;25:366-76

35 Pritchard MA, de Dassel T, Beller E, et al. Autism in toddlers born very preterm. Pediatrics 2016;137:1-8.

36 Johnson S, Marlow N. Preterm birth and childhood psychiatric disorders. Pediatr Res 2011;69:11R-8R

37 Johnson $\mathrm{S}$, Hollis $\mathrm{C}$, Kochhar $\mathrm{P}$, et al. Psychiatric disorders in extremely preterm children: longitudinal finding at age 11 years in the EPICure study. J Am Acad Child Adolesc Psychiatry 2010;49:453-63.e1.

38 Treyvaud K, Ure A, Doyle LW, et al. Psychiatric outcomes at age seven for very preterm children: rates and predictors. I Child Psychol Psychiatry 2013:54:772-9.

39 Burnett AC, Anderson PJ, Cheong J, et al. Prevalence of psychiatric diagnoses in preterm and full-term children, adolescents and young adults: a meta-analysis. Psychol Med 2011:41:2463-74.

40 Farooqi A, Hägglöf B, Sedin G, et al. Mental health and social competencies of 10to 12 -year-old children born at 23 to 25 weeks of gestation in the 1990s: a Swedish national prospective follow-up study. Pediatrics 2007;120:118-33.

41 Ure AM, Treyvaud K, Thompson DK, et al. Neonatal brain abnormalities associated with autism spectrum disorder in children born very preterm. Autism Res 2016:9:543-52.

42 Mulder H, Pitchford NJ, Marlow N. Inattentive behaviour is associated with poor working memory and slow processing speed in very pre-term children in middle childhood. Br J Educ Psychol 2011:81:147-60.

43 Aarnoudse-Moens CS, Weisglas-Kuperus N, Duivenvoorden $\mathrm{HJ}$, et al. Executive function and IQ predict mathematical and attention problems in very preterm children. PLOS ONE 2013;8:e55994.

44 Loe IM, Feldman HM, Huffman LC. Executive function mediates effects of gestational age on functional outcomes and behavior in preschoolers. J Dev Behav Pediatr 2014:35:323-33.

45 Quigley MA, Poulsen G, Boyle E, et al. Early term and late preterm birth are associated with poorer school performance at age 5 years: a cohort study. Archives Dis Child Fetal Neonatal Ed 2012:97:F167-73.

46 Mathiasen R, Hansen BM, Andersen AM, et al. Gestational age and basic school achievements: a national follow-up study in Denmark. Pediatrics 2010;126: e1553-61.

47 Saigal S, den Ouden L, Wolke D, et al. School-age outcomes in children who were extremely low birth weight from four international population-based cohorts. Pediatrics 2003:112:943-50.

48 Hutchinson EA, De Luca CR, Doyle LW, et al. Victorian Infant Collaborative Study G. School-age outcomes of extremely preterm or extremely low birth weight children. Pediatrics 2013:131:e1053-61.

49 Anderson P, Doyle LW. Neurobehavioral outcomes of school-age children born extremely low birth weight or very preterm in the 1990s. JAMA 2003;289:3264-72.

50 Taylor HG, Klein N, Anselmo MG, et al. Learning problems in kindergarten students with extremely preterm birth. Arch Pediatr Adolesc Med 2011;165:819-25. 
51 Johnson S, Wolke D, Hennessy E, et al. Educational outcomes in extremely preterm children: neuropsychological correlates and predictors of attainment. Dev Neuropsychol 2011;36:74-95.

52 Litt JS, Gerry Taylor H, Margevicius S, et al. Academic achievement of adolescents born with extremely low birth weight. Acta Paediatr 2012;101:1240-5.

53 Petrou S, Abangma G, Johnson S, et al. Costs and health utilities associated with extremely preterm birth: evidence from the EPICure study. Value Health 2009;12:1124-34

54 Wolke D, Samara M, Bracewell M, et al. Specific language difficulties and school achievement in children born at 25 weeks of gestation or less. J Pediatr 2008;152:256-62.

55 Simms V, Cragg L, Gilmore C, et al. Mathematics difficulties in children born very preterm: current research and future directions. Archives Dis Child Fetal Neonatal Ed 2013;98:F457-63.

56 Lindström K, Winbladh B, Haglund B, et al. Preterm infants as young adults: a Swedish national cohort study. Pediatrics 2007;120:70-7.

57 Saigal S. Functional outcomes of very premature infants into adulthood. Semin Fetal Neonatal Med 2014;19:125-30.

58 Hack M. Young adult outcomes of very-low-birth-weight children. Semin Fetal Neonatal Med 2006;11:127-37.

59 Moster D, Lie RT, Markestad T. Long-term medical and social consequences of preterm birth. N Engl J Med 2008;359:262-73.

60 Eryigit Madzwamuse S, Baumann N, Jaekel J, et al. Neuro-cognitive performance of very preterm or very low birth weight adults at 26 years. J Child Psychol Psychiatry 2015;56:857-64.

61 Løhaugen GC, Gramstad A, Evensen KA, et al. Cognitive profile in young adults born preterm at very low birthweight. Dev Med Child Neurol 2010;52:1133-8.

62 Burnett A, Davey CG, Wood SJ, et al. Extremely preterm birth and adolescent mental health in a geographical cohort born in the 1990s. Psychol Med 2014:44:1533-44.
63 Halmøy A, Klungsøyr K, Skjaerven $\mathrm{R}$, et al. Pre- and perinatal risk factors in adults with attention-deficit/hyperactivity disorder. Biol Psychiatry 2012;71: 474-81.

64 Lindström K, Lindblad F, Hjern A. Psychiatric morbidity in adolescents and young adults born preterm: a Swedish national cohort study. Pediatrics 2009;123:e47-53.

65 Nosarti C, Reichenberg A, Murray RM, et al. Preterm birth and psychiatric disorders in young adult life. Arch Gen Psychiatry 2012;69:E1-8.

66 Hallin AL, Stjernqvist K. Follow-up of adolescents born extremely preterm: self-perceived mental health, social and relational outcomes. Acta Paediatr 2011;100:279-83.

67 Eryigit-Madzwamuse S, Strauss V, Baumann N, et al. Personality of adults who were born very preterm. Archives Dis Child Fetal Neonatal Ed 2015;100:F524-9.

68 Breeman LD, Jaekel J, Baumann N, et al. Attention problems in very preterm children from childhood to adulthood: the Bavarian Longitudinal Study. J Child Psychol Psychiatry 2016;57:132-40.

69 Treyvaud K, Doyle LW, Lee KJ, et al. Parenting behavior at 2 years predicts school-age performance at 7 years in very preterm children. $J$ Child Psychol Psychiatry 2016;57:814-21.

70 Spittle A, Orton J, Anderson PJ, et al. Early developmental intervention programmes provided post hospital discharge to prevent motor and cognitive impairment in preterm infants. Cochrane Database Syst Rev 2015;(11):CD005495.

71 Melby-Lervåg $\mathrm{M}$, Hulme C. Is working memory training effective? A meta-analytic review. Dev Psychol 2013;49:270-91.

72 Roberts G, Quach J, Spencer-Smith M, et al. Academic outcomes 2 years after working memory training for children with low working memory: a randomized clinical trial. JAMA Pediatr 2016;170:e154568.

73 Johnson S, Gilmore C, Gallimore I, et al. The long-term consequences of preterm birth: what do teachers know? Dev Med Child Neurol 2015;57:571-7.

74 Jaekel J, Strauss VY, Johnson S, et al. Delayed school entry and academic performance: a natural experiment. Dev Med Child Neurol 2015;57:652-9. 